Bangl. J. Vet. Med. (2008). 6 (1): 01-05

\title{
ISOLATION, IDENTIFICATION, TOXIN PROFILE AND ANTIBIOGRAM OF ESCHERICHIA COLI ISOLATED FROM BROILERS AND LAYERS IN MYMENSINGH DISTRICT OF BANGLADESH
}

\author{
M. T. Hossain, M. P. Siddique*, F. M. A. Hossain, M. A. Zinnah, M. M. Hossain ${ }^{1}$, M. K. Alam, M. T. Rahman \\ and K. A. Choudhury \\ Department of Microbiology and Hygiene, Bangladesh Agricultural University, Mymensingh-2202, \\ ${ }^{1}$ Department of Medicine and Surgery, Sylhet Agricultural University, Sylhet \\ *Corresponding author’s e-mail: mpsiddique77@gmail.com
}

\begin{abstract}
The study was conducted to isolate and identify E. coli from apparently healthy broilers and layers from different poultry farms adjacent to the Bangladesh Agricultural University, Mymensingh, Bangladesh, during the period of January to May 2006 and characterize their ability to produce enterotoxin and also the antibiogram of the isolates. A total of 110 fecal samples were collected from broiler $(\mathrm{n}=55)$ and layer $(\mathrm{n}=55)$ chickens. E. coli were isolated and identified by cultural, biochemical, motility test and the heat-stable toxins were determined by Infant Mouse Assay (IMA). In case of broilers, 35 (63.6\%) samples were found positive while 31 (56.4\%) from layers. The overall prevalence of $E$. coli was $60 \%$. Among the isolates of $E$. coli, $22.86 \%$ isolates from broiler and $38.71 \%$ isolates from layer were found positive for their ability to produce enterotoxin based on mice inoculation test. The antibiotic sensitivity pattern showed that the isolates were highly sensitive to chloramphenicol, ciprofloxacin, kenamycin and cephalexin and an increasing trend of resistance was recorded in both broiler and layer isolates. It may be concluded from the results of this study that the high resistance of $E$. coli to antibiotics constitutes a threat to poultry industry in Bangladesh.
\end{abstract}

Key words: E. coli, toxin, antibiogram

\section{INTRODUCTION}

Major species of $E$. coli encounter in the lower portion of the intestine of human, warm blooded animals and birds, where they are mostly responsible for gastroenteritis (Pelczar et al., 1986). E. coli produces two distinct enterotoxins: a high-molecular weight, immunogenic, heat labile toxin (LT) and/or a low-molecular weight, nonimmunogenic, heat stable toxin (ST) (Greenberg and Guerrant, 1986; Robertson et al., 1986). The LTs of E. coli from human and porcine origin have been shown to share a common structure that activates adenylate cyclase and cross reacts immunologically with the heat-labile enterotoxin of Vibrio cholerae. These enterotoxins have been serogrouped as LT-1 (Pickett et al., 1986). LT-11 a variant of LT-1 has recently been isolated from some isolates of E. coli. The LT-11 has characteristics that are similar to those of LT-1 but that are different in their antigenic specificity (Holmes et al., 1996). Two types of heat stable enterotoxins (STs) have been described, based on their methanol solubilities: a methanol-soluble molecule with biologic activity in suckling mice, rats and piglets (referred to as STa) and a methanol-insoluble molecule with biological activity in piglets (referred to as STb) (Greenberg and Guerrant, 1986).

In Bangladesh, for many years, antibiotic is randomly used for treatment purpose. There is clear evidence of abuse of antibiotics, for which emergence of multi-drug resistant E. coli are continuously increasing (Hussain et al., 1982; Nazir et al., 2005). This leads to indiscriminate use of antimicrobial drugs in poultry industry without prior testing that might have resulted antibiotic resistance causing a serious problem because it limits the therapeutic possibilities in the treatment of bacterial disease. So, the research work was undertaken to isolating and identify E. coli from chicken, their toxin profile analysis and antibiogram nature. 


\section{MATERIALS AND METHODS}

The whole study was performed in three steps in the bacteriology laboratory of Department of Microbiology and Hygiene, Bangladesh Agricultural University (BAU), Mymensingh, during the period of January to May 2006. The first step includes characterization of the E. coli. The second step leads to toxin profile analysis and the third step includes the antibiogram.

\section{Isolation of E. coli}

A total of 110 fecal samples from healthy broiler $(n=55)$ and layer $(n=55)$ chickens were collected from different poultry farms adjacent to BAU, with the help of sterile cotton buds and transferring the buds immediately to sterile nutrient broth. The samples were wrapped with ice, kept in box, and transferred within 30 minutes.

\section{Identification of the isolates}

The isolates of E. coli were identified by observing gross colony morphology using Eosin Methylene Blue (EMB) agar, McConkey Agar, Salmonella-Shigella (SS) agar, Grams staining properties and motility as described by Merchant and Packer (1967). The isolates were subjected to different biochemical tests such as sugar fermentation test, Indole production test, Methyl-Red and Voges-Proskauer (MR-VP) test, following the standard methods described by Cowan (1985). Pure culture of E. coli was isolated using EMB agar.

\section{Maintenance of stock culture}

Nutrient agar slants were used to maintain the stock culture for each of the $E$. coli isolate. The E. coli were inoculated in the slant by streaking and were incubated at $37^{\circ} \mathrm{C}$ for 24 hours. Finally, glycerol was overlaid and the culture was kept at room temperature.

\section{Toxin profile}

Overnight broth cultures were centrifuged at $1300 \mathrm{rpm}$ for 15-20 minutes and supernatants were collected and transferred into new vials, then gentamycin was added @ $5 \mu \mathrm{g} / \mathrm{ml}$ and kept at room temperature for overnight, following the method described by Gianella (1976). The purity of the toxins were tested by streaking the supernatants on EMB agar and incubated at $37^{\circ} \mathrm{C}$ for 24 hours. If no colony was formed, then the supernatant was used for detection of heat-stable (ST) toxin by Infant Mouse Assay (IMA).

\section{Enterotoxigenic effect in suckling mice and determination of ST toxin by IMA}

Sixty Swiss Albino suckling mice of 1-4 days old were separated from their mother immediately before used and divided into two groups A and B consisting of three mice in each group. An amount of $2.5 \mu \mathrm{l}$ crude culture supernatant containing suspected enterotoxin were administered to the mice of group A through oral route with the help of micropipette. Mice of group B were kept as control. Mice were incubated at $37^{\circ} \mathrm{C}$ for 24 hours to observe toxic effects.

IMA was used for the detection of heat-stable toxin. Day old Swiss Albino suckling mice were used for the test which were inoculated with $0.1 \mathrm{ml}$ of crude culture supernatant and kept at room temperature for 4 hours, then sacrificed by cervical dislocation. The abdomen was opened and the entire intestine was removed. The weight of the gut and the remaining carcass were taken and the ratio was calculated for each mouse. The average ratio of less than 0.070 was considered negative while $0.070 \sim 0.085$ was considered positive for ST toxin (Gianella, 1976).

\section{Antibiotic sensitivity test}

Antibiotic sensitivity test of isolated $E$. coli was performed with the standardized commercial sensitivity discs (Mast Diagnostics, Mast group Ltd., Merseyside, UK) following Disc Diffusion Method (Bauer et al., 1966). Sensitivity to antibiotic was studied on blood agar plates with ampicillin (10 $\mu \mathrm{g} / \mathrm{disc})$, cephalexin (30 $\mathrm{\mu g} / \mathrm{disc})$ chloramphenicol (30 $\mu \mathrm{g} / \mathrm{disc})$, ciprofloxacin (5 $\mu \mathrm{g} / \mathrm{disc})$, erythromycin (15 $\mu \mathrm{g} / \mathrm{disc})$, kanamycin (30 $\mu \mathrm{g} / \mathrm{disc})$ and nalidixic acid (30 $\mu \mathrm{g} / \mathrm{disc})$. An amount of 0.5 freshly grown pure culture of E. coli was poured on blood agar plates and allowed to spread gently over the entire surface with a glass rod spreader. After 1 to 2 minutes, the discs were placed at a distance of about $1 \mathrm{~cm}$ apart and incubated at $37^{\circ} \mathrm{C}$ for overnight. On the basis of the diameter of zones of inhibition produced around the antibiotic discs the inhibitory effect of the antibiotic to the growth of the culture was recorded as resistance, less sensitive $(1.0-1.5 \mathrm{~mm})$, moderately sensitive (3.0-3.5 mm) and highly sensitive (6.0-6.5 mm). 
Toxin profile and antibiogram of Escherichia coli

\section{RESULTS AND DISCUSSION}

Isolation and identification of $\mathrm{E}$. coli

The results of gross colony morphology on EMB agar, McConkey agar and SS agar, Grams staining and motility test are summarized in Table 1.

Table 1. Identifying characteristics of E. coli

\begin{tabular}{|c|c|c|c|c|c|c|}
\hline \multirow{2}{*}{$\begin{array}{l}\text { Source } \\
(n=55)\end{array}$} & \multirow[t]{2}{*}{ Motility } & \multicolumn{3}{|c|}{ Colony characteristics } & \multirow[t]{2}{*}{ Morphology } & \multirow{2}{*}{$\begin{array}{l}\text { Staining } \\
\text { properties }\end{array}$} \\
\hline & & EMB agar & McConkey agar & SS agar & & \\
\hline $\begin{array}{l}\text { Broiler } \\
\text { feces }\end{array}$ & + & $\begin{array}{l}\text { Yellow green } \\
\text { metallic sheen }\end{array}$ & $\begin{array}{l}\text { Bright pink or } \\
\text { red colonies }\end{array}$ & $\begin{array}{l}\text { Pinkish } \\
\text { colony }\end{array}$ & $\begin{array}{l}\text { Short rod, single, pair or } \\
\text { in short chain }\end{array}$ & Gram negative \\
\hline $\begin{array}{l}\text { Layer } \\
\text { feces }\end{array}$ & + & $\begin{array}{l}\text { Yellow green } \\
\text { metallic sheen }\end{array}$ & $\begin{array}{l}\text { Bright pink or } \\
\text { red colonies }\end{array}$ & $\begin{array}{l}\text { Pinkish } \\
\text { colony }\end{array}$ & $\begin{array}{l}\text { Short rod, single, pair or } \\
\text { in short chain }\end{array}$ & Gram negative \\
\hline
\end{tabular}

$\mathrm{n}=$ Number of $E$. coli isolates.

For biochemical characterization, a series of biochemical tests selective for E. coli were performed with the suspected Gram-negative rod shaped bacteria. All the isolates fermented the five basic sugars producing acid and gas. All the isolates were Methyl Red positive, Voges-Proskauer test negative and Indole test positive. Out of 110 samples, 66 samples were found to be positive for $E$. coli isolates. The prevalence of $E$. coli in the faecal sample was $60.0 \%$ (Table 2). Bhattacharjee et al. (1996) reported $40.82 \%$ prevalence of $E$. coli in chicken from Bangladesh but Nazir (2004) stated the over all prevalence was $62.5 \%$ from chicken, which is closed to the present findings.

Table 2. Prevalence of E. coli in broiler and layer chickens

\begin{tabular}{|llll|}
\hline Sources of samples & Total samples examined & Samples positive & Prevalence (\%) \\
\hline Broiler & 55 & 35 & 63.6 \\
Layer & 55 & 31 & 56.4 \\
\hline Total & 110 & 66 & 60.0 \\
\hline
\end{tabular}

\section{Toxin profile}

Enterotoxigenic E. coli (ETEC) were detected based on mortality and survivability of 1-4 day old mice (60) within 24 hours of postinoculation. Out of 35 broiler isolates, 8 (22.86\%) E. coli were found positive for ETEC. Out of 31 layer isolates, 12 (38.71\%) were found positive for their enterotoxigenicity. It can be speculated that the toxic effects could be due to heat-labile (LT) toxin (Yamamoto and Yokota, 1983). Positive results of ETEC denoted in the following (Table 3).

Table 3. Prevalence of ETEC

\begin{tabular}{|c|c|c|c|c|c|c|c|}
\hline \multirow[t]{2}{*}{ Source } & \multicolumn{3}{|c|}{ Crude culture supernatant (toxin) } & \multirow[t]{2}{*}{ Positive effect } & \multirow{2}{*}{$\begin{array}{l}\text { No. of isolates } \\
\text { tested }\end{array}$} & \multicolumn{2}{|c|}{ Positive for ETEC } \\
\hline & Quantity & Route & Incubation & & & Number & $\%$ \\
\hline Broiler & $25 \mu \mathrm{l}$ & Oral & 24 hours & Death $(3 / 3)$ & 35 & 8 & 22.86 \\
\hline Layer & $25 \mu \mathrm{l}$ & Oral & 24 hours & Death (3/3) & 31 & 12 & 38.71 \\
\hline Total & & & & & 66 & 20 & 30.3 \\
\hline
\end{tabular}


The results of IMA showed that all the $E$. coli isolates, tested in IMA, were found negative for ST (Table 4). In case of broiler isolates the obtained value (gut weight and carcass weight ratio) ranged from 0.092 to 0.103 and in case of layer isolates 0.095 to 0.114 .

Table 4. Determination of heat-stable (ST) toxin by IMA

\begin{tabular}{|c|c|c|c|c|c|c|}
\hline \multirow[t]{2}{*}{ Source } & \multicolumn{3}{|c|}{ Crude culture supernatant (toxin) } & \multicolumn{2}{|c|}{ Gut weight and carcass weight ratio } & \multirow[t]{2}{*}{ Results } \\
\hline & Quantity & Route & Incubation & $\begin{array}{l}\text { Ranges of standard } \\
\text { value }\end{array}$ & $\begin{array}{l}\text { Ranges of obtained } \\
\text { value }\end{array}$ & \\
\hline Broiler & $0.1 \mathrm{ml}$ & Oral & 4 hours & 0.070 to 0.085 & 0.092 to 0.103 & ST-Negative \\
\hline Layer & $0.1 \mathrm{ml}$ & Oral & 4 hours & 0.070 to 0.085 & 0.095 to 0.114 & ST-Negative \\
\hline
\end{tabular}

\section{Antibiogram nature of $E$. coli}

Among the $E$. coli isolated from broilers, $100 \%$ were resistant to nalidixic acid, $97.14 \%$ to cloxacillin, $91.42 \%$ to erythromycin and $62.85 \%$ to ampicillin and these findings were almost similar to the reports of Nazir et al. (2005). Though, Prescott and Baggot (1993) reported good activity of erythromycin against some gram negative bacteria. About $91.43 \%$ broiler isolates were moderately sensitive to cephalexin, $77.74 \%$ to ciprofloxacin and $85.71 \%$ to kanamycin while $54.28 \%$ isolates were highly sensitive to chloramphenicol and $45.71 \%$ were moderately sensitive to the same antibiotic. On the other hand, $14.29 \%$ and $22.86 \%$ isolates were highly sensitive to kanamycin and ciprofloxacin respectively (Table 5), whereas Al-Ghamdi et al. (2001) found 34.7\% resistant to ciprofloxacin. Fasihuddin and Khatoon (1994) also the resistancy of E. coli isolates against common antibiotics.

Among the E. coli isolated from layers, 100\% were resistant to cloxacillin and nalidixic acid and 93.55\% isolates were resistant to erythromycin which are similar to the findings of Al-Ghamdi et al. (2001). A total of $32.26 \%$ layer isolates were found resistant to Ciprofloxacin and 25.81\% to Ampicillin (Table 5). Nazir et al. (2005) also recorded the same findings. Islam et al. (2004) recorded an increasing trend of resistance in broilers than in ducks due to indiscriminate use of antibiotics in Bangladesh (Hussain et al., 1982).

Table 5. Antibiotic sensitivity and resistance pattern of $E$. coli isolates

\begin{tabular}{|c|c|c|c|c|c|c|c|c|}
\hline \multirow[t]{2}{*}{ Source of E. coli } & \multicolumn{2}{|l|}{ Resistance } & \multicolumn{2}{|c|}{ Less sensitive } & \multicolumn{2}{|c|}{ Moderately sensitive } & \multicolumn{2}{|c|}{ Highly sensitive } \\
\hline & Antibiotic & $\%$ & Antibiotic & $\%$ & Antibiotic & $\%$ & Antibiotic & $\%$ \\
\hline \multirow[t]{4}{*}{ Broiler } & $\mathrm{OB}$ & 97.14 & $\mathrm{AP}$ & 37.15 & $\mathrm{~K}$ & 85.71 & $\mathrm{C}$ & 54.28 \\
\hline & NA & 100 & $\mathrm{E}$ & 8.58 & CL & 91.43 & CIP & 22.86 \\
\hline & $\mathrm{AP}$ & 62.85 & OB & 2.86 & CIP & 77.74 & $\mathrm{~K}$ & 14.29 \\
\hline & $\mathrm{E}$ & 91.42 & - & - & $\mathrm{C}$ & 45.71 & CL & 8.57 \\
\hline \multirow[t]{6}{*}{ Layer } & OB & 100 & AP & 75.19 & $\mathrm{C}$ & 50 & $\mathrm{~K}$ & 32.26 \\
\hline & NA & 100 & $\mathrm{E}$ & 6.45 & CL & 64.52 & $\mathrm{C}$ & 25 \\
\hline & CIP & 32.26 & CIP & 58.06 & $\mathrm{~K}$ & 48.39 & - & - \\
\hline & $\mathrm{E}$ & 93.55 & $\mathrm{~K}$ & 19.39 & CIP & 9.68 & - & - \\
\hline & $\mathrm{AP}$ & 25.81 & CL & 35.48 & - & - & - & - \\
\hline & - & - & $\mathrm{C}$ & 25 & - & - & - & - \\
\hline
\end{tabular}

$\mathrm{AP}=$ Ampicillin, $\mathrm{C}=$ Chloramphenicol, $\mathrm{CL}=$ Cephalexin, $\mathrm{CIP}=$ Ciprofloxacin, $\mathrm{OB}=$ Cloxacillin, $\mathrm{E}=$ Erythromycin, $\mathrm{K}=$ Kanamycin and NA = Nalidixic acid. 
Among the E. coli isolated from layer, $32.26 \%$ were highly sensitive and $64.52 \%$ moderately sensitive to kanamycin and cephalexin respectively. A total of $25 \%$ and $19.39 \%$ layer isolates were less sensitive to chloramphenicol and kanamycin respectively. However $25 \%$ isolates were found highly sensitive to chloramphenicol (Table 5). These findings are similar to the reports of Prasad et al. (1997). So, it may be concluded that the prevalence of E. coli in fecal samples from broilers and layer chickens and that of ETEC among the isolates remain worth of taking serious note of it and the antibiogram nature of the isolates is quite significant in respect of indiscriminate use of antibacterial drugs.

\section{REFERENCES}

1. Al-Ghamdi MS, El-Morsy F, Al-Mustofa ZH, Faiz M and Al-Ramadhan M (2001). Bacterial organisms isolated from healthy chicken in the Entran Province of Saudi Arabia and their pattern of resistance to antimicrobial agents. Scientific Journal of King Faisal University 2: 14-21.

2. Bauer AW, Kirby WMM, Sheris JC and Truck M (1966). Antibiotic susceptibility testing by a standardized single disc method. Americal Journal of Clinical Pathology 145: 225-230.

3. Bhattacharjee PS, Kundu RL, Biswas RK, Mazumder JU, Hossain E and Miah AH (1996). A retrospective analysis of chicken diseases diagnosed at the Central Diaease Investigation Laboratory, Dhaka, Bangladesh. Bangladesh Veterinary Journal 30: 105-113.

4. Cowan ST (1985). Cowan and Steel's manual for identification of medical bacteria. $2^{\text {nd }}$ edn., Cambridge University Press, Cambridge, London. pp. 138-139.

5. Gianella RA (1976). Suckling mouse model for detection of heat stable Escherichia coli enterotoxin: characteristics of the model. Infection and Immunity 14(1): 95-99.

6. Greenberg RN and Guerrant RL (1986). Heat stable enterotoxin. In: Pharmacology of bacterial toxins. F. Dorner J. Drews (eds). Pergamon Press, Elmsford, New York. pp. 115-151.

7. Holmes RK, Twiddy EM and Pickett CL (1996). Purification and characterization of type 11 heat-labile enterotoxin of E. coli. Infection and Immunity 53: 464-473.

8. Hussain MM, Glass RJ and Khan MR (1982). Antibiotics used in a rural community in Bangladesh. International Journal of Epidemiology 11: 402-405.

9. Islam MT, Islam MA, Samad MA and Kabir SML (2004). Characterization and antibiogram of E. coli associated with mortality in broilers and ducklings in Bangladesh. Bangladesh Journal of Veterinary Medicine 2: 09-14.

10. Merchant IA and Packer RA (1967). Veterinary Bacteriology and Virology. $7^{\text {th }}$ edn., The Iowa State University Press, Ames, Iowa, USA. pp. 211-305.

11. Nazir KHMNH (2004). Molecular base of diversified Escherichia coli isolates potentiating antibiotic resistant pattern and compromising epidemiology. MS Thesis submitted to the Department of Microbiology and Hygiene, Bangladesh Agricultural University, Mymensingh.

12. Nazir KHMNH, Rahman MB, Nasiruddin KM, Akhtar F, Khan MFR and Islam MS (2005). Antibiotic sensitivity of Escherichia coli isolated from water and its relation with plasmid profile analysis. Pakistan Journal of Biological Science 8: 1610-1613.

13. Pelczar JR, Michel J, Krieg NR and Chan ECS (1986). Microbiology. $5^{\text {th }}$ edn., pp. 272.

14. Pickett CL, Twiddy EM, Belisle BW and Holmes RK (1986). Cloning of genes that encode a new heat-labile enterotoxin of E. coli. Journal of Bacteriology 165: 348-352.

15. Prasad V, Murthym KK and Rao TVJ (1997). In vitro antibiogram studies of E. coli in chicken. Indian Veterinary Journal 74: 616-617.

16. Prescott JF and Baggot JD (1993). Lincosamides, Macrolides and pleuromutilins; Antimicrobial Therapy. In: Veterinary Medicine. $2^{\text {nd }}$ edn., Ames, Iowa State University Press. pp. 179-204.

17. Robertson DC, McDonel JL and Dorner F (1986). Heat-labile enterotoxin. In: Pharmacology of bacterial toxins. F Dorner and J Drews (eds). Pergamon Press, Elmsford, New York. pp. 77-113.

18. Yamamoto T and Yokota T (1983). Plastids enterotoxigenic Escherichia coli HI0407: evidence of two heat stable enterotoxin genes and a conjugal transfer system. Journal of Bacteriology 153: 1352-1360. 